\title{
The Implementing Geological Disposal Technology Platform - addressing the needs of new Member States
}

\author{
R. Kowe ${ }^{1, *}$, J. Delay ${ }^{2}$, M. Hammarström ${ }^{3}$, T. Beattie ${ }^{4}$ and M. Palmu ${ }^{5}$ \\ 1 Radioactive Waste Management, Harwell, Oxford, UK \\ 2 Agence National pour la Gestion des Déchets Radioactifs, Bure, France \\ 3 Svensk Kärnbränslehantering $\mathrm{AB}$, Stockholm, Sweden \\ 4 MCM-Consulting, UK \\ 5 Posiva Oy, Olkiluoto, Eurajoki, Finland
}

[Received 10 October 2014; Accepted 16 February 2015; Associate Editor: Kath Morris]

\section{ABSTRACT}

The Implementing Geological Disposal of Radioactive Waste Technology Platform (IGD-TP) was launched in November 2009 to facilitate international cooperation in common areas of research, development and demonstration (RD\&D) with a view to advancing the implementation of geological disposal facilities for spent fuel, high-level and other long-lived waste in Europe.

The IGD-TP's Vision is that "by 2025, the first geological disposal facilities for spent fuel, high-level waste and other long-lived radioactive waste will be operating safely in Europe". Aside from most European waste management organisations, the IGD-TP currently has 124 members covering most of the RD\&D actors in the field of implementing geological disposal of radioactive waste in Europe.

Five years after its inception, the IGD-TP has been shown to play a leading role in coordinating joint actions for RD\&D in radioactive waste geological disposal programmes. The work of the platform takes into account differences between the timing and challenges for the respective waste management programmes. Following implementation of Posiva's geological disposal facility in Finland it is expected that within the next 5 years the construction of the Swedish and French geological disposal facilities will commence. Within IGD-TP, the SecIGD2 project whose remit is "Coordination and Support Action under the $7^{\text {th }}$ Framework programme" aims at supporting, at the European level, the networking and structuring of RD\&D programmes and competences in countries with less advanced geological disposal programmes, including those in the new European Union Member States. Furthermore, the SecIGD2 supports the development and coordination of the necessary competences to meet the Vision 2025 as a part of the platform's Competence Maintenance, Education and Training (CMET) working group.

KEYWoRDs: nuclear waste management, geological disposal, technology platform.

\section{Introduction}

THE Implementing Geological Disposal of Radioactive Waste Technology Platform (IGD-

*E-mail: raymond.kowe@nda.gov.uk

DOI: 10.1180/minmag.2015.079.6.34
TP) was launched in November 2009 with a vision that "by 2025, the first geological disposal facilities for spent fuel, high-level waste and other long-lived
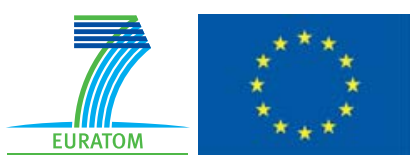

The publication of this research has been funded by the European Union's European Atomic Energy Community's (Euratom) Seventh Framework programme FP7 (2007-2013) under grant agreements $n^{\circ} 249396$, SecIGD, and $n^{\circ} 323260$, SeclGD2. 
radioactive waste will be operating safely in Europe" ('Vision 2025' (IGD-TP, 2009)). Aside from most European waste management organisations (WMOs), the IGD-TP currently has 124 members covering most of the research, development and demonstration (RD\&D) actors in the field of implementing geological disposal in Europe.

The main objectives of the IGD-TP are to initiate and carry out collaborative actions in Europe to facilitate the stepwise implementation of safe, deep geological disposal of spent fuel, high-level waste, and other long-lived radioactive waste by solving the remaining scientific, technological and social challenges, and thereby supporting the wastemanagement programmes in the Member States. The platform intends to enhance confidence in the

TABLE 1. List of current and planned EC projects supported by IGD-TP.

\begin{tabular}{|c|c|}
\hline EC project & Description \\
\hline Lucoex & $\begin{array}{l}\text { Large Underground Concept } \\
\text { Experiments }\end{array}$ \\
\hline First-Nuclides & $\begin{array}{l}\text { Fast/Instant Release of Safety } \\
\text { Relevant Radionuclides from } \\
\text { Spent Nuclear Fuel }\end{array}$ \\
\hline REDUPP & $\begin{array}{l}\text { Reducing Uncertainties in } \\
\text { Performance Prediction }\end{array}$ \\
\hline DOPAS & $\begin{array}{l}\text { Full-Scale Demonstration of } \\
\text { Plug And Seals }\end{array}$ \\
\hline PEBS & $\begin{array}{l}\text { Long-term Performance of } \\
\text { Engineered Barrier Systems }\end{array}$ \\
\hline MoDeRn & $\begin{array}{l}\text { Monitoring Developments for } \\
\text { safe Repository operation and } \\
\text { staged Closure }\end{array}$ \\
\hline BELBaR & $\begin{array}{l}\text { Bentonite Erosion: effects on } \\
\text { the Long term performance } \\
\text { of the engineered Barrier and } \\
\text { Radionuclide transport }\end{array}$ \\
\hline SecIGD2 & Secretariat IGD-TP \\
\hline CAST & CArbon-14 Source Term \\
\hline $\begin{array}{l}\text { Submitted for } 2014- \\
2015 \text { H2020 call }\end{array}$ & Description \\
\hline Cebama & $\begin{array}{l}\text { Cement-based materials, } \\
\text { properties, evolution, barrier } \\
\text { functions }\end{array}$ \\
\hline MIND & $\begin{array}{l}\text { Impact of microbial } \\
\text { metabolism on the safety of } \\
\text { geological repositories }\end{array}$ \\
\hline MODERN2020 & $\begin{array}{l}\text { Repository operational } \\
\text { monitoring programme }\end{array}$ \\
\hline
\end{tabular}

solutions and implementation of geological disposal, to reduce overlapping work, to produce savings in total costs of RD\&D, and to make better use of existing competences and research infrastructures (Ouzounian et al., 2012).

The IGD-TP developed a Strategic Research Agenda (SRA) (IGD-TP, 2011a) in order to achieve the joint common vision. This work, the guidelines for which were derived from the vision and from the licensing needs of the implementing organizations, was led by the implementing organizations. It was driven by the idea that the Key Topics identified in the SRA would focus on activities that are of common interest and would benefit from joint implementation. As these founding documents were developed, the stakeholders started to deploy the SRA with the aim of facilitating the stepwise implementation of safe deep geological disposal of spent fuel and high level waste in Europe. The action plan for the SRA's implementation is described in a Deployment Plan (DP) (IGD-TP, 2011b).

The IGD-TP Secretariat has, to date, coordinated the launch of nine European projects and is also coordinating three additional technical and scientific working groups that may evolve into projects in the framework of the Horizon 2020 2014-2015 work programme and what may follow; these are shown in Table 1. The SecIGD2 project is a coordination and support action co-financed by an EC Grant from Euratom's 7th Framework programme. The aim of the SecIGD2 project is to support the work of the Secretariat to enhance, integrate and coordinate the activities of IGD-TP members.

In addition to providing the secretariat for IGDTP, the SecIGD2 helps to network, structure and develop RD\&D competences in countries with less advanced geological disposal programmes. This action has been set up specifically to help the RD\&D in these countries to meet the requirements of the European 'Waste Directive' (European Commission, 2011).

Another SecIGD2 work package supports the development and coordination of the required competences to meet the Vision 2025 as a part of the platform's Competence Maintenance, Education and Training working group (CMET).

\section{Working group on RD\&D dissemination}

\section{Remit}

This work package led by the UK's Radioactive Waste Management Limited (RWM) focuses on 
looking at different ways of transferring strategic knowledge on how to set up and maintain wastemanagement programmes spanning those Member States which are close to licensing, to those Member States which are not planning to submit licence applications prior to 2025 .

This work package was set up specifically to support Member States with different pace and degrees of advancement in implementation of their respective national programmes for geological disposal of nuclear waste. The key policy driver is the legal requirement for Member States to fulfil the relevant requirements of the Waste Directive (European Commission, 2011). Thus the work package aims to: provide specific support to a working group in charge of networking, structuring and developing RD\&D competences in countries with less advanced geological disposal programmes; provide the management guidelines for Joint Activities resulting from this working group; support the organization of two events (including Geodisposal, 2014) for disseminating the scientific and technical information and results derived from the IGD-TP's Joint Activities and from other RD\&D efforts in the field of geological disposal; specifically to provide support to members of countries with less advanced programmes to develop their role within the technology platform; and further develop the IGD-TP's SRA.

\section{Activities}

The working group on RD\&D dissemination which was set up in February 2013 has 21 participants from 14 countries including seven new Member States. Meetings were held to identify the specific needs of the less advanced programmes and to develop topics which would go into the management guidelines.

A first action was to submit a questionnaire. New Member States were asked to identify which key topics, cross-cutting activities and wastemanagement programme-specific activities in the SRA and the Deployment Plan (DP) were of interest to their programme, and also which topics they are interested in which are outside the scope of the SRA and DP. This information will be used to: identify the specific needs of the less advanced programmes and analyse how they could be taken into account in the IGD-TP Joint Activities; identify key open reference or state-of-the-art documentation used by more advanced programmes; prepare proposals to implement these needs in the existing Technical Scientific Working Group/Organizational Working Group in the technology platform; and identify areas of possible technology transfer through specific agreements between more and less advanced programmes.

The outcome of the questionnaire is shown in Fig. 1. The responses to the questionnaire were communicated to the 4th IGD-TP Exchange Forum in Prague in October 2013.

\section{Future work}

The group decided that the information dissemination needs identified in the questionnaire could be met by setting out a guide to help less advanced programmes establish, progress and implement RD\&D to support their geological disposal programmes. The guide will explore if topics/ information needs identified by the questionnaire that are not fundamental RD\&D should be included (such as costing and inventory methodologies, etc.). It was suggested that this document could also serve as a roadmap for the less advanced programmes to help develop their RD\&D programme and respond specifically to Requirement (f) of Article12 (1) of the Council Directive 2011/70/ Euratom. The roadmap is also intended to complement the NAPRO guide.

The outline structure of the guide will set out 'typical' stages and steps involved with developing and implementing a successful geological disposal programme for radioactive wastes, known hereafter as 'key stages towards implementation'. These key stages towards implementation of geological disposal need to be mapped out to allow less advanced programmes to understand and define their own priorities and where specific IGD-TP activities fit into the 'bigger' picture. It was agreed by the working group that the guide will:

- set-out the high-level steps of an RD\&D programme to support geological disposal at a national strategic level;

- contain background information on the waste directive in which RD\&D is one of the eleven requirements;

- include an introductory chapter which outlines the requirements for countries to develop a strategy for an RD\&D programme;

- focus on what the RD\&D needs are to support the safety case at different steps, i.e. what RD\&D needs are typically prioritized at a 


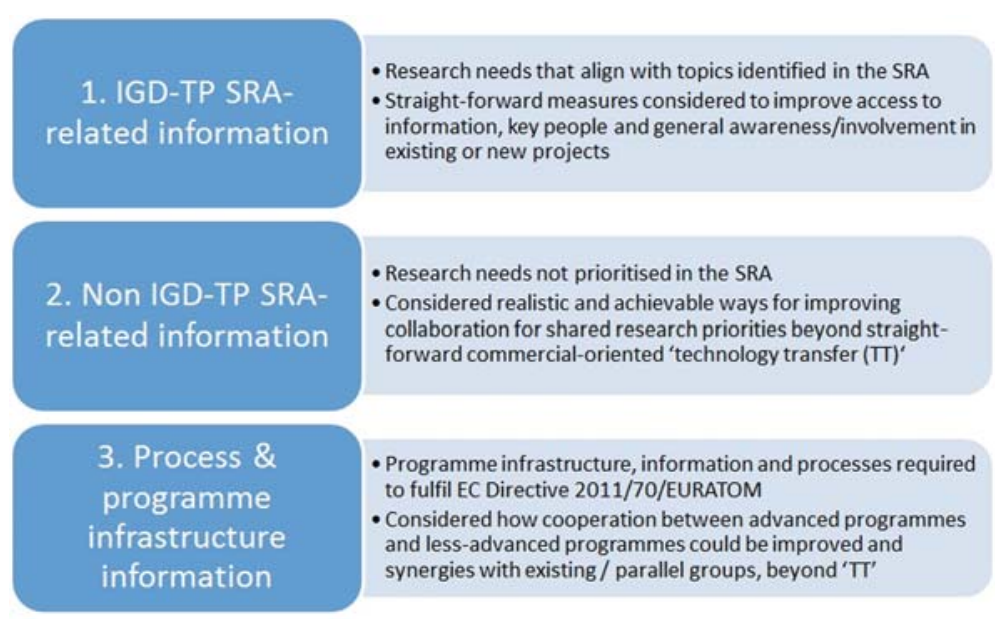

FIG. 1. Identified needs of less advanced programmes.

generic phase (without a site), during a siting process/site selection, after site selection and concept selection, needs for final licensing, etc. (note that safety-case methodology is considered complete for more advanced programmes though they still continue carrying out safetycase R\&D);

- contain an illustration of how long it takes to develop an RD\&D programme and the need to develop it in stages (1, 2, 3 yearly) based on an example of a developed programme (e.g. ANDRA); and

- draw on the state-of-the-art RD\&D carried out by waste management organizations and European Commission projects to set-out what information is available to support development of the safety case at the different stages of implementation.

Other information needs that do not relate to fundamental $\mathrm{RD} \& \mathrm{D}$ can be met through programme-specific projects and/or technology transfer (e.g. costing models, inventory codes, and process and infrastructure development).

The guide will be presented at a one-day event planned in May 2015. A key requirement to implementing a waste-management programme will be to establish a workforce with expertise across several scientific and technical disciplines related to geological disposal and maintaining the competence of such staff. It is expected, therefore, that the working group on RD\&D dissemination will liaise with the CMET working group in the future.

\section{Competence Maintenance, Education and Training (CMET)}

\section{Remit}

This Work Package is led by Posiva Oy. The IGDTP has identified in its SRA the need for Competence Maintenance, Education and Training (CMET) as one of the cross-cutting activities supporting the Vision 2025, with particular emphasis on facilitating access to expertise and technology and maintaining competence of Member States.

The CMET working group was established in 2012 to help address this need. The group consists of 30 volunteers from 14 different European countries representing six different stakeholder groups from 27 different organizations sharing the common interest of maintaining and developing competence in geological disposal.

The Terms of Reference of the CMET working group were updated in 2013. However, the objectives of the working group remain unchanged and are: to carry out the transfer of the state-of-theart strategies and activities for competence maintenance, education and training related to the implementation of Vision 2025; to promote quality assurance of training for professionals and education and training programmes including the development of a voluntary accreditation (taking advantage of the European Credit system for Vocational Education and Training (ECVET) approach); to develop the training requirements 
for implementation of the SRA; and to ensure indirectly that training providers and new personnel will be available.

\section{Activities}

The working group is focused on two major activities: producing the group's Strategy and Action Plan (StrAP), and carrying out a feasibility study on a voluntary accreditation scheme.

The production of the CMET StrAP is scheduled for completion by the end of 2014. The purpose of the StrAP is to identify and partly address the tasks required in the field of competence maintenance, education and training to progress towards Vision 2025. In practice, a set of tasks to meet the CMET group's objectives will be carried out with the aim of implementing the SRA and the IGD-TP's first
Deployment Plan until 2016. A first step was to issue a brief questionnaire covering the on-going Joint Activities. The group has also strong interactions with the training providers in the geological disposal community via links to the European Fission Training Schemes, in particular, with the Petrus3 (Programme for Education, Training and Research on Underground Storage) project (ENEN, 2014).

The second main output from the group will be a feasibility study for a voluntary accreditation scheme. This work will take advantage of the pilot actions running in the European Union related to the implementation of the European Credit system for Vocational Education and Training (ECVET) (Chenel Ramos, 2012). The ECVET approach (shown in Fig. 2) sets out the learning outcomes that need to be mastered by professionals,

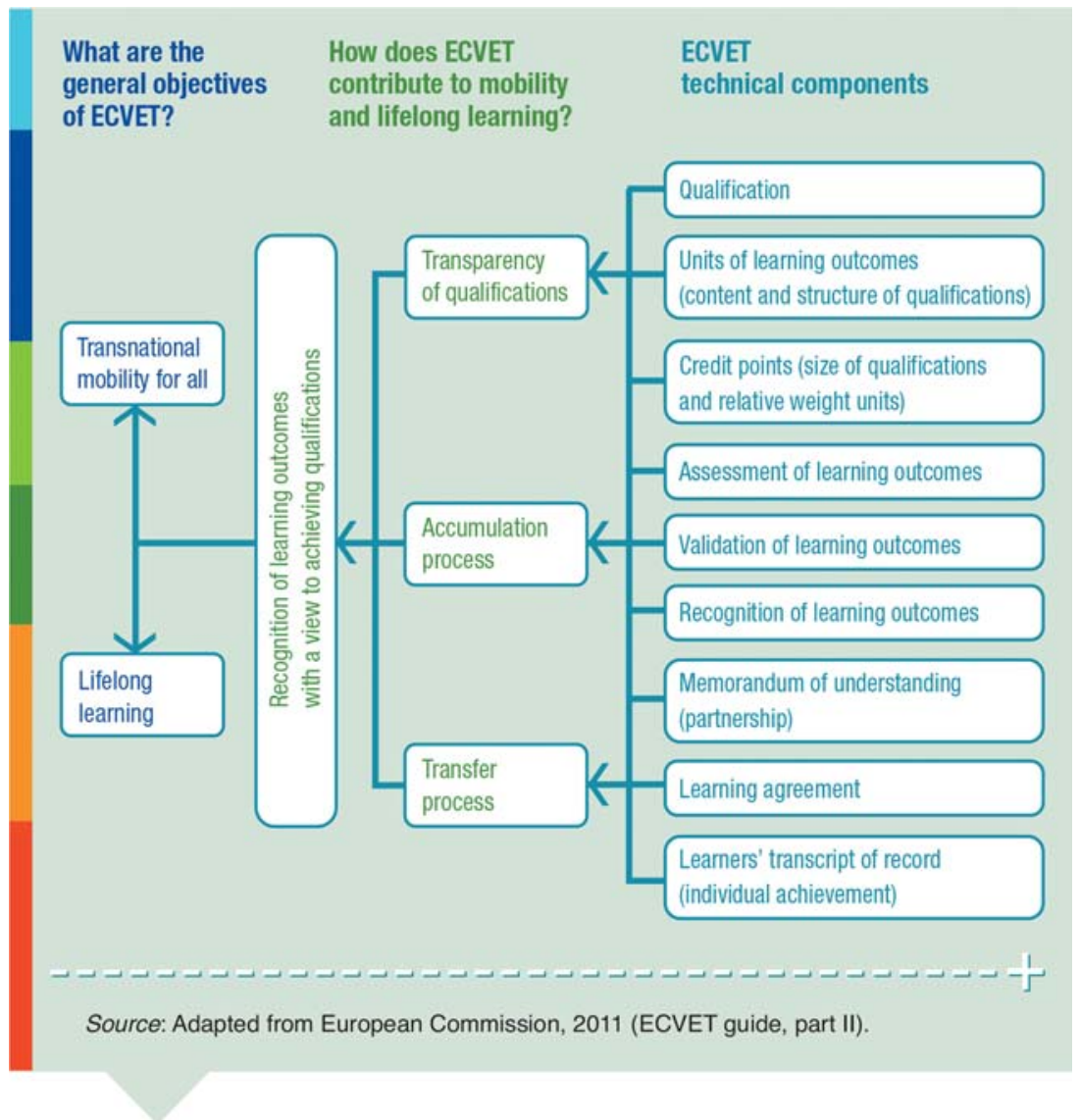

FIG. 2. ECVET objectives and technical components (reproduced with the permission of Cedefop). 
starting from the early stages of a waste management programme, to running nuclear-waste facilities safely and efficiently. Learning outcomes are defined in terms of the relevant Knowledge, Skills and Competence (KSC). In their different job functions or tasks, professionals will need to demonstrate these $\mathrm{KSCs}$ to specified European qualification levels.

In geological disposal, several on-going programme-level education and training activities in Europe already exist. A considered approach to define a generic accreditation scheme for geological disposal is desirable as this would facilitate both students' and professionals' mobility amongst European countries. CMET is currently investigating the feasibility of using the ECVET approach as a common accreditation process for certification of training schemes across a network of European institutions.

In addition, use of a systematic process such as ECVET to identify and document the KSCs required by the geological disposal community also serves as a means of maintaining key knowledge in the nuclear industry over the long timeframes which are characteristic of a repository development (Palmu et al., 2013).

\section{Future work}

In the future, further ways of carrying out competence maintenance, education and training promotion will be required at different stages of repository development programmes. It is important to start capturing the Knowledge, Skills and Competence accumulated in geological disposal over the decades of research and technological development by documenting and making the education and training needs for new professionals more transparent.

Given the timescales for implementation of geological disposal of the order of tens to hundreds of years a proportion of the work force will retire with a resultant associated loss of knowledge and skills. At the same time the waste-management sector will be competing with other sectors of industry for young graduate employees. The maintenance and sustainability of the available pool of expertise and specialization in the wastemanagement sector is therefore crucial. The establishment of committed and systematic Knowledge, Skills and Competence (KSC) encompassing scientific programmes that satisfy the WMOs needs would help address this skill shortage. The challenge remains to get the WMOs to recognize the benefits of a structured approach to defining the Knowledge, Skills and Competence in geological disposal.

\section{Conclusions}

Within the European geological disposal community, the IGD-TP, through its Secretariat SecIGD2, will continue to create opportunities to carry out joint Research Development and Demonstration of safe solutions in geological disposal of radioactive waste. Therefore, the SecIGD2 is expected to build competence and to disseminate knowledge amongst stakeholders concerned with radioactive waste management and with geological disposal in particular.

The work in this paper has reported on two specific work packages in the SecIGD2 to facilitate efficient knowledge transfer between countries in different stages of their waste-management programmes.

- The first to network, structure and develop Research, Development and Demonstration (RD\&D) programmes and competencies countries with less advanced geological disposal programmes and how their needs can be integrated into the IGD-TP Strategic Research Agenda and future activities.

- The second supports the Competence Maintenance, Education and Training (CMET) group whose aim is to establish a coherent framework of training schemes aiming at addressing the shortage in engineers and researchers in the field of geological disposal that may occur in the future.

\section{Acknowledgements}

The authors thank the European Commission. The research leading to these results received funding from the European Union's European Atomic Energy Community's (Euratom) Seventh Framework programme FP7 (2007-2013) under grant agreements $\mathrm{n}^{\circ} 249396$, SecIGD, and n`323260, SecIGD2.

\section{References}

Chenel Ramos, C. (2012) The Preparation of an ECVEToriented Nuclear Job Taxonomy: Concept and Progress Report. EHRO-N report. JRC Scientific and Policy Reports. Luxembourg: Publications Office of the European Union. JRC77735, EUR 25644 EN, ISBN 978-92-79-27888-4 (pdf), ISSN 1831-9424 
(online), doi:10.2790/71302, available at http://ehron. jrc.ec.europa.eu/ [accessed September 2014].

ENEN (2014) http://www.enen-assoc.org/en/training/ petrus-iii.html [accessed September 2014].

European Commission (2011) COUNCIL DIRECTIVE 2011/70/Euratom of 19 July 2011 establishing a Community framework for the responsible and safe management of spent fuel and radioactive waste.

IGD-TP (2009) Implementing Geological Disposal of Radioactive Waste Technology Platform. Vision Report, available at http://www.igdtp.eu [accessed September 2014], also available as EUR 24160 EN. Luxembourg: Publications Office of the European Union. ISBN 97892-79-13622-1, ISSN 1018-5593, doi 10.2777/53840.

IGD-TP (2011a) Implementing Geological Disposal of Radioactive Waste Technology Platform Strategic Research Agenda 2011-2016, July 2011, ISBN 97891-979786-0-6, available at http://www.igdtp.eu.
IGD-TP (2011b) IGD-TP Implementing Geological Radioactive Waste Technology Platform Deployment Plan 2011-2016, June 2012, ISBN 97891-979786-1-3, available at http://www.igdtp.eu.

Ouzounian, G., Palmu, P.M. and Eng, T.L. (2012) Implementing Geological Disposal of Radioactive Waste Technology Platform. From the Strategic Research Agenda to its Deployment. 12015. Proceedings of WM2012 Conference, 26 February-1 March 2012, Phoenix, Arizona, USA.

Palmu, P.M., Cantone, M.C., Paiva, I. and Vivalda, C. (2013) The CMET Working Group actions within IGD-TP. Feasibility of voluntary accreditation in geological disposal using ECVET approach. NESTet 2013 Conference, 17-21 November 2013, Madrid, Spain. Published in NESTet 2013 transactions available at http://www.euronuclear.org/events/nestet/ nestet2013/transactions.htm 